\title{
ANALYSIS OF PROBLEMS OF BIOMASS GRINDER INTEGRATED WITH BRIQUETTING PLANT
}

\author{
Ajay Kumar Choubey ${ }^{1}$, Anil Kumar Dubey ${ }^{2}$, P L Singh ${ }^{3}$ \\ ${ }^{1}$ Research Associate, ${ }^{2}$ Principal Scientist, ${ }^{3}$ Senior Scientist, Central Institute of Agricultural Engineering, Bhopal, India, \\ alja1y@yahoo.co.in,dubey@ciae.res.in, pannalalsingh24@gmail.com
}

\begin{abstract}
In briquetting plant, briquettes are produced through small pieces of soybean stalk, pigeon pea straw, lantana stalk, cotton stalk with moisture content below 10\%. Biomass grinding machine is an important part of the briquetting plant, whose function is to convert aggregate material in to small pieces. Biomass grinder consists of mainly hammer, grate and shaft. Shaft is an essential component of grinding machine, when holds hammers, pulley and fan. The failures of shaft bearing were observed due to non uniform distribution of stress. The study was under taken to conduct simulation study of shaft for stress analysis with the help of FE software ANSYS 12.0.1.
\end{abstract}

Keywords: Biomass Grinder, FEM, Stress-strain, Stepped Shaft

\section{INTRODUCTION}

Briquetting is a process in which the material is compressed and density of the material increases 10 times $\left(1000 \mathrm{~kg} / \mathrm{m}^{3}\right)$. The densification depends upon two parameters: size of particles and pressure of machine. The equipments used for size reduction are thresher, hammer mill etc. The particle size reduced by thresher from $1 \mathrm{~mm}$ to $10 \mathrm{~mm}$ and where as through hammer mill $0.2 \mathrm{~mm}$ to $1 \mathrm{~mm}$. The fine particles of biomass improve the quality and density of briquettes. A briquetting plant, used to produce the briquettes from crop residues essentially have grinder (hammer mill) consists of a rotating shaft with free- swinging hammers, which reduce the size of particle to a predetermined size through a perforated screen. [1-2]

The hammer mill had hammer-like projection mounted on a shaft. The hammer revolves at high speed and grinds the materials fed into pieces by beating. The one end of shaft coupled with blower to transport the powder material from mill. The fineness of particles depends on the speed of shaft and the size of perforated screen. The projection of hammers and side mounting of blower create uneven stresses results in failure of shaft. The latest development had replaced the normal shaft by high frequency shaft with more reliable operation. The shaft of hammer mill coupled with blower. The shaft was driven by electrical motors and the rotational speeds could only be varied by changing either the transmission ratio or the number of driven poles by electrical switches. [3-6]
The Finite Element Method (FEM) is a very powerful tool for simulation of the engineering problems. The objective of this study is to develop a finite element (FE) model of the stepped shaft. The simulations of static and harmonic response on shaft are conducted by ANSYS 12.0.1 software. The static and harmonic results are analyzed and verified by simulation results.

The study was focused to investigate the effect of rotational speed on stresses developed on shaft fitted with hammer. The effect of pressure on shaft and effect of rotational speed on failure limit of shaft was also studied.

\section{METHODOLOGY}

The approach adopted for analysis of shaft through ANSYS software is shown in figure 1 . The proposed analysis focus on creation of a 3-D FE model and defining input parameters required for analysis of shaft. The input parameters used for study were rotational speed and forces on the shaft. The boundary conditions were defined at the end of the shaft as "all degree of freedom (dof)" was fixed. 


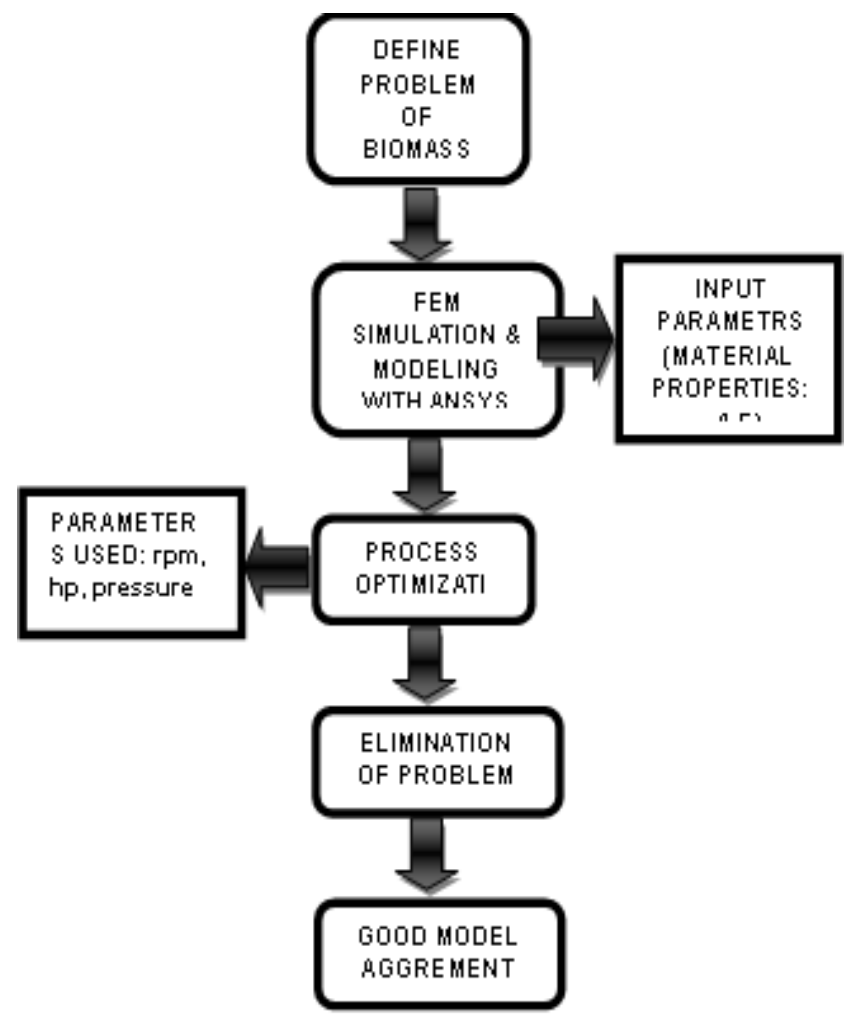

Fig-1: Flow chart of study

The material parameter such young's modulus and poisson's ratio for static condition was fixed considering the material of shaft as given in table 1 . The shaft of the hammer mill is show in figure 2 .

Table -1: Material properties of shaft

\begin{tabular}{|l|l|}
\hline Property & value \\
\hline Material & Steel \\
\hline Poisson's ratio $(v)$ & 0.30 \\
\hline Density $(\rho)$ & $7890 \mathrm{~kg} / \mathrm{m} 3$ \\
\hline Young modulus(E) & $210000 \mathrm{MPa}$ \\
\hline UTS & $410 \mathrm{MPa}$ \\
\hline
\end{tabular}

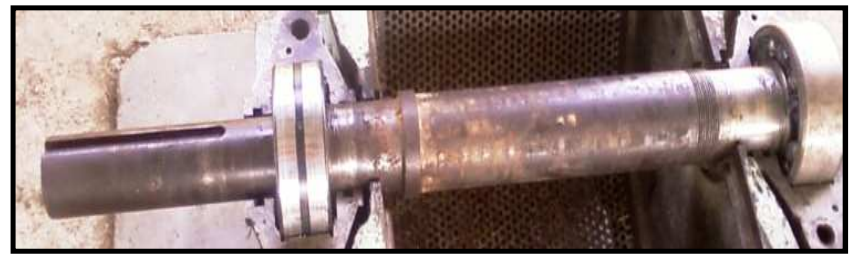

Fig- 2: View of Shaft supported by bearing

\section{FINITE ELEMENT MODELING}

The 3-D FE model for shaft was developed by using ANSYS 12.0.1 software. The shaft is analyzed by ANSYS in three steps. First step involves meshing of the object and feeding input of material properties of shaft in software. The shaft had converted into 64,944 elements and12,958 nodes. The nodes and element of the shaft is shown in figure 3. Second step involves selection of analysis type i.e. static, dynamic etc. and putting the boundary condition of loading and displacement in term of degree of freedom at the end occurring on shaft and then the running the ANSYS software to get the analysed result in form stress vs rotational speed. The third step gives the analyzed result in graphical form, color band for exceeding the limit and result summary.

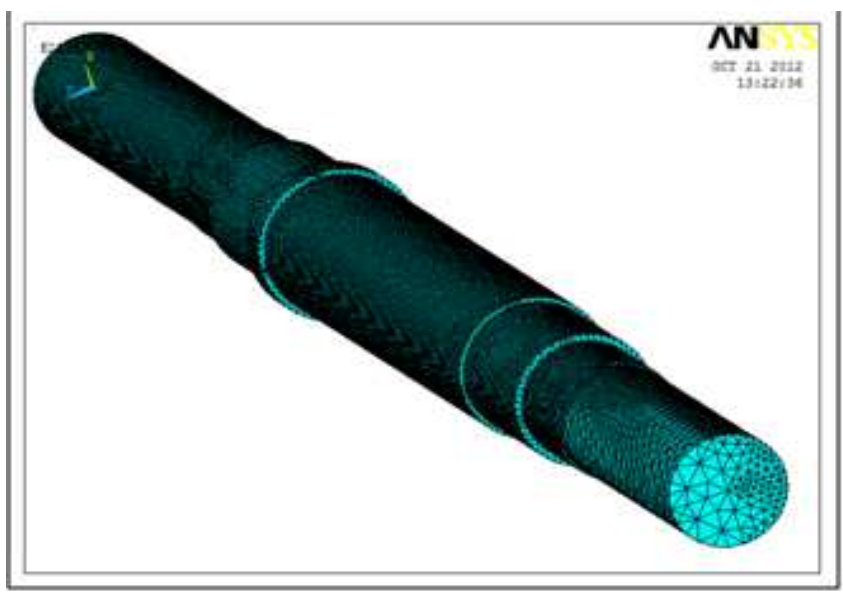

Fig- 3: Meshing of Shaft

The length of the shaft studied was $771 \mathrm{~mm}$ having varying diameter ranging from 48 to $60 \mathrm{~mm}$. The detail of the shaft is shown in figure 4.

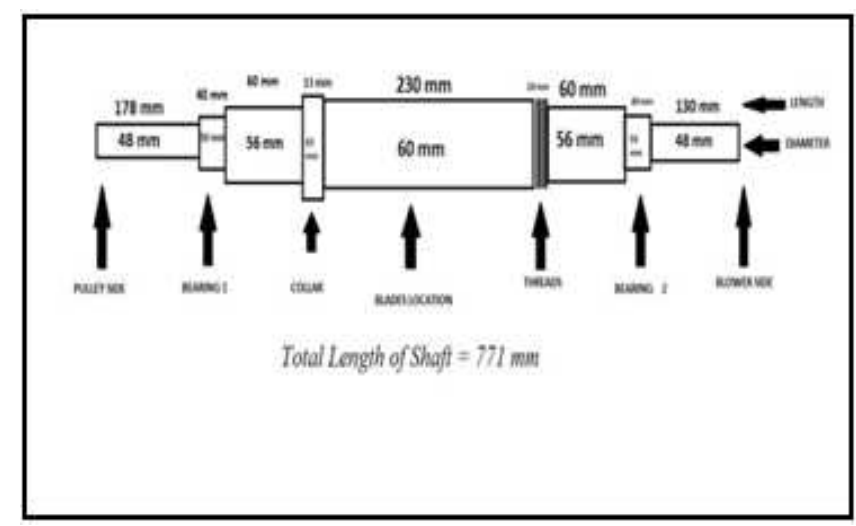

Fig- 4: Line diagram for hammer mill shaft 


\section{RESULTS \& DISCUSSION}

The results of static and dynamic analysis of hammer mill shaft through ANSYS software is presented below.

\subsection{Static Analysis}

The shear stress observed after analysis is shown in figure 5 . The results showed that the maximum shear stress occurred at point where blower was fitted whereas other end of shaft has minimum shear stress. The effect of pressure on change in shear stress was analyzed in the software. The result observed is shown in figure 6 . As the pressure increases the shear stress and von-Mises stress increases. The increase in pressure after $0.025 \mathrm{MPa}$ the rate of increasing of von-Mises stress and shear stress was very high.

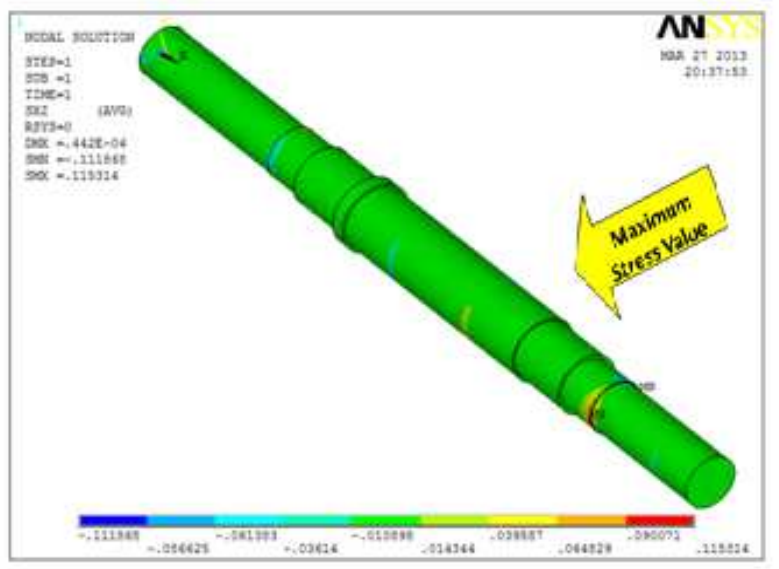

Fig- 5: Shear stress (Max. 0.115314, Min. -0.111868)

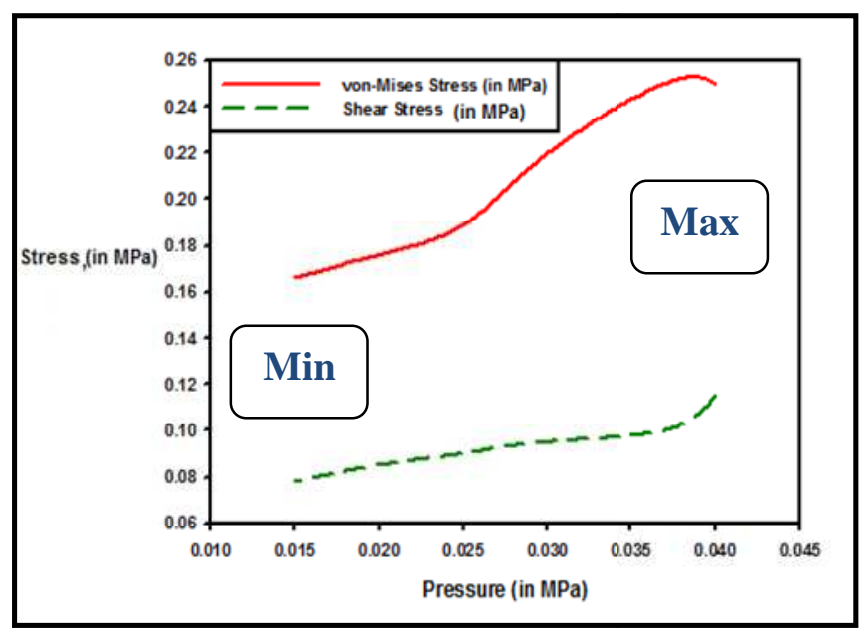

Fig- 6: Effect of pressure on von-Mises stress and shear stress

\subsection{Harmonic Analysis}

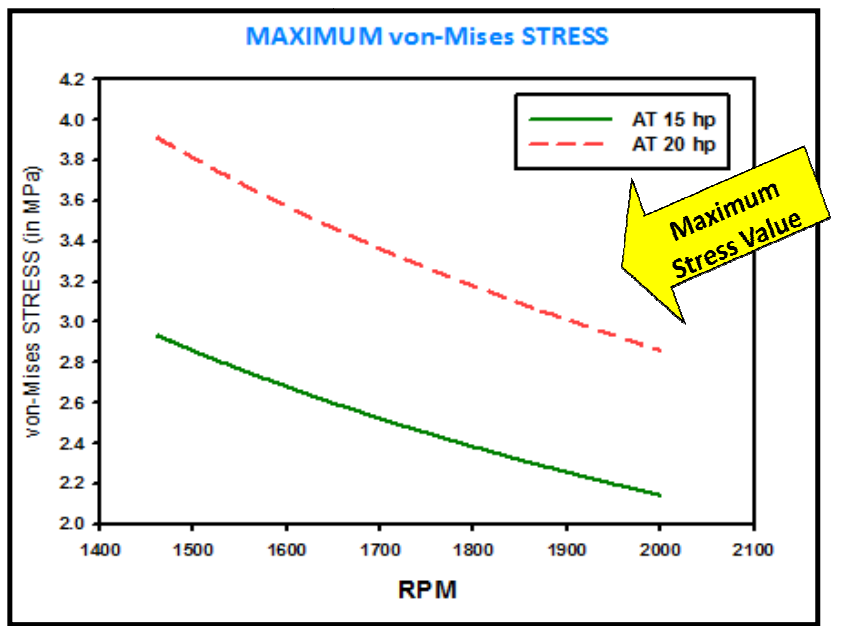

Fig- 7: Effect of rotational speed on von-Mises stress

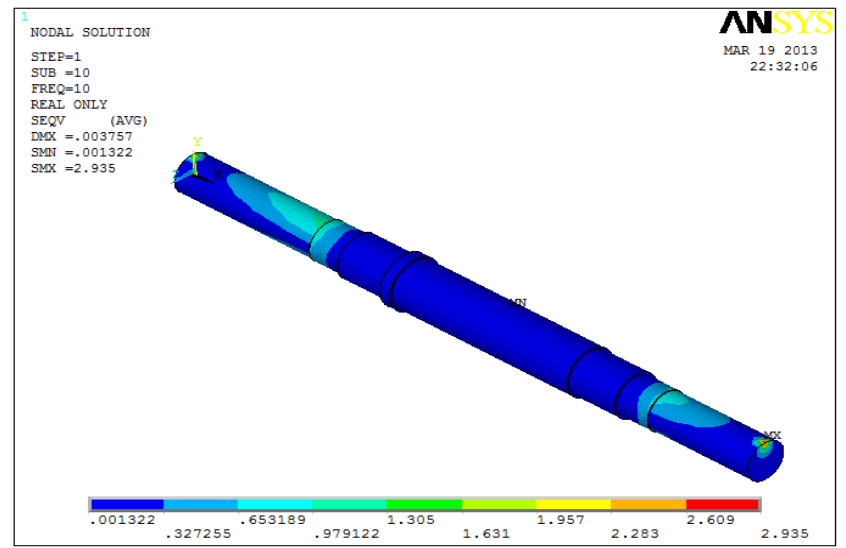

Fig-8: von-Mises stress at $2000 \mathrm{rpm}, 20 \mathrm{hp}$

$($ Max. value $=2.935 \mathrm{MPa}$, Min. value $=0.0013 \mathrm{MPa})$

The dynamic behaviour of shaft was analysed using harmonic response analysis featured of software The shaft were analyzed in the speed range of 1400 to $2000 \mathrm{rpm}$. Considering the constant power requirement of the system for the given work output.The increase in the speed of shaft von-Mises stress is reduced. The shaft speed vs von-Mises stress is shown in figure 7.

The change in von-Mises stress on shaft at 1460 and 2000 rpm with $15 \mathrm{~kW}$ is shown in figure 8 and 9 respectively. The high rotational speed of shaft has shown in lower von-Mises stress hence reduce the failure possibility. The change in shear stress with change in rotational speed is given in table 2. 


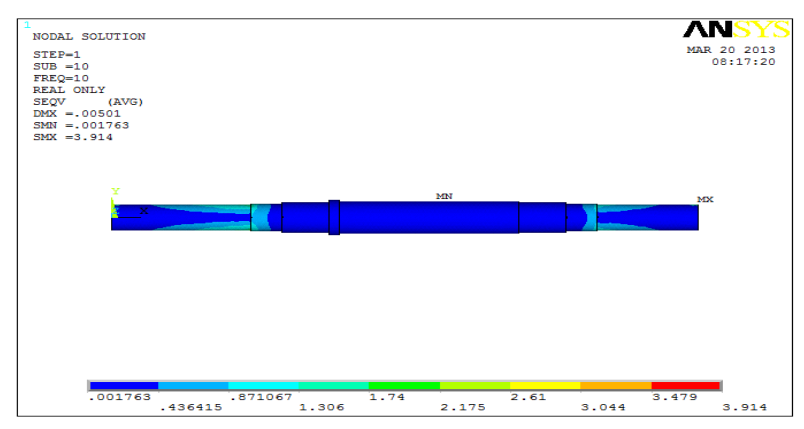

Fig- 9: von-Mises stress at $1460 \mathrm{rpm}, 20 \mathrm{hp}$ $($ Max. value $=3.91 \mathrm{MPa}$, Min. value $=0.0017 \mathrm{MPa})$

Table- 2: Value of Shear stress

\begin{tabular}{|l|l|l|l|l|}
\hline \multirow{2}{*}{ RPM } & hp & \multicolumn{2}{|c|}{$\begin{array}{l}\text { Shear Stress } \\
\text { (in MPa) }\end{array}$} & \multirow{2}{*}{ differences } \\
\cline { 3 - 4 } & & Max. & Min. & \\
\hline 1460 to 2000 & 15 & 0.38 & 0.28 & 0.1 \\
\hline 1460 to 2000 & 20 & 0.51 & 0.38 & 0.13 \\
\hline
\end{tabular}

\section{CONCLUSIONS}

The analysis study conducted on hammer mill stepped shaft concluding:

i. The shear stress of shaft at blower end was maximum causing the failure. The stress could be reduced by reducing the load on the shaft at blower end or reducing the pressure by change the diameter of shaft.

ii. The dynamic behavior of shaft indicates that the high speed operation of machine could reduce the vonMises and shear stress on the shaft resulting in to safe operation.

\section{REFERENCES}

[1]. A. Nasir, "Development and Testing of a Hammer Mill", AU J.T., Vol. no. 8, Issue no. 3, Page no. 124-130, 2005.

[2]. Ariavie G. O, Ebunilo P. O., Obanor A. I.,"Design and preliminary testing of a hammer mill with endsuction lift capability suitable for commercial processing of grains and solid minerals in Nigeria", International Journal of Engineering Science and Technology, Vol. no. 2, Issue no. 6, Page no. 1581-1593, 2010.

[3]. Anup A. Bijagare, P.G. Mehar and V.N. Mujbaile, "Design optimization \& analysis of drive shaft", VSRD International journal of mechanical, automobile and production engineering, Vol. no. 2, Issue no. 6, Page no. 210215, 2012.

[4] Barry Dupen, "Applied Strength of Materials for Engineering Technology", 48-50, 2012.
[5]. Chetan T Rathod, Walmiki S Rathod, "Design and Analysis of Two Roller Sugar mill using FEA Techniques", International Journal of Scientific Engineering and Technology, Vol. no.1, Issue no.3, Page no. 148-152, 2012. [6]. Deping Liu, Hang Zhang, Zheng Tao and Yufeng Su, "Finite Element Analysis of High-Speed Motorized Spindle Based on ANSYS", The Open Mechanical Engineering Journal, Vol. no. 5, Page no. 1-10, 2011.

[7]. Jaimin Brahmbhatt, Abhishek choubey, "Design and analysis of crankshaft for single cylinder 4-stroke diesel engine", International Journal of Advanced Engineering Research and Studies, Vol. 1, Issue 4, Page no. 88-90, 2012.

[8]. K.V.N. Parvathi , CH. Prabhakara Rao, "Structural design of composite drive shaft for rear-wheel drive engine", International Journal of Advanced Engineering Research and Studies, Vol. 2, Issue 1, 85-89, 2012.

[9]. R. P. Kumar Rompicharla, K.Rambabu, "Design and analysis of drive shaft with composite materials" Research Expo International Multidisciplinary Research Journal, Vol no. 2, Issue no. 2, Page no. 178 -187, 2012.

[10]. S. S. Salaskar, K. H. Inamadar, "Design and Manufacturing of Twin Lobe Roots Blower using steel shaft", International Journal of Engineering Research and Applications, Vol. no. 2, Issue no. 4, Page no. 266-270, 2012.

\section{BIOGRAPHIES}

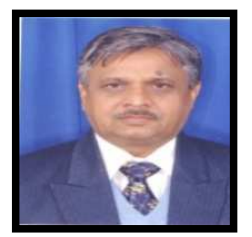

Dr A. K. Dubey is working as a Principal Scientist at the Central Institute of Agricultural Engineering (CIAE), Bhopal in the area of renewable energy. CIAE is one of the premier institutions in India. $\mathrm{He}$ has about 23 years experience in the area of research. He has more than 30 research publications in national and international journals and proceedings. He had completed $\mathrm{PhD}$ from Maulana Azad National Institute of Technology, Bhopal, India.

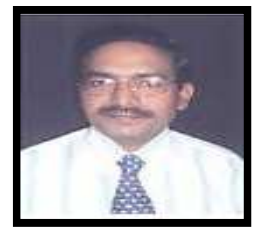

Dr P. L. Singh is working as a Senior Scientist at the Central Institute of Agricultural Engineering, Bhopal, India in the area of renewable energy. He has about 18 years experience in the area of research and extension. He has more than 25 research publications in national and international journals and proceedings. He had completed PhD from Maulana Azad National Institute of Technology, Bhopal, India.

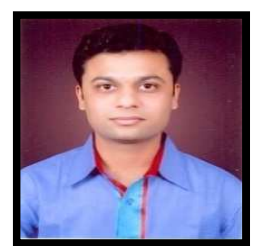

Ajay Kumar Choubey is working as a Research Associate at the Central Institute of Agricultural Engineering, Bhopal. He had completed M. Tech. from Maulana Azad National Institute of Technology, Bhopal, India. 